\title{
INVISIBILIDAD DE LA MUJER MEXICANA EN LA DOCUMENTACIÓN DE MEDIADOS DEL SIGLO XVIII (COLONIA DEL NUEVO SANTANDER)
}

\section{Invisibility of the Mexican woman in the mid-I $8^{\text {th }}$ century documents (the Colony of New Santander)}

\author{
Helena Vales-Villamarín Navarro \\ Universidad Internacional de La Rioja \\ Correo-e: helenavalesvillamarin@attendis.com
}

Recepción: 3 de junio de 20I6. Envío a informantes: 14 de marzo de 2017 Aceptación definitiva: 22 de febrero de 2018

Resumen: La posición histórica y social de las mujeres, subordinadas o invisibilizadas por los modos dominantes de producción y por las relaciones sociales, empieza a cuestionarse durante la etapa ilustrada, aunque es un proceso lento y desigual.

Mostramos el resultado de la investigación sobre la presencia de la mujer en la Colonia del Nuevo Santander (Virreinato de Nueva España), último territorio en ser realmente colonizado por la Corona española a mediados del siglo XviII.

Somos conscientes de lo concreto del territorio estudiado, zona de frontera del Imperio español, y del corto espacio de tiempo, los 20 primeros años desde la creación de la Colonia en I748. Se quiere mostrar una instantánea de la vida cotidiana de las mujeres, pero la realidad es su ausencia en la documentación escrita.

Palabras Clave: mujer; educación; Ilustración; méxico; siglo XviII.

AвSTRACT: The social and historical position of women, subordinated or made invisible by the dominant ways of production and by the social relations, begins to be questioned during the enlightened era, although it is a slow and unequal process.

We show the research results about the presence of women in the Colony of New Santander (Viceroyalty of New Spain), the last territory really colonized by the Spanish Crown in the middle of the i8th century. 
We are aware of the concretion of the studied territory, a bordering area of the Spanish Empire, and of the short period of time, the first 20 years since the creation of the Colony in 1748 . We aim to show a snapshot of women daily life, but their absence in the written documents is a fact.

KEY wORDS: woman; education; the Enlightenment; Mexico; i8th century.

\section{Introducción}

L

A HISTORIA DE LA MUJER en la América colonial está en vías de escribirse, contiene muchas lagunas y plantea cuestiones que permanecen sin contestar. Mucho de lo que sabemos sobre la mujer en las colonias hispanoamericanas refleja la vida de la alta sociedad. La investigación actual permite comenzar a ampliar la visión y establecer similitudes o diferencias en las formas de vida, ambientes sociales, motivaciones y objetivos entre las mujeres de diferente condición y etnia ${ }^{\mathrm{I}}$.

Un momento crucial para la instrucción de la mujer fue la Ilustración. Se legislaba para que se iniciara la incorporación de la mujer a la escuela y así poder desempeñar el papel que se esperaba de ella en el ámbito familiar. Las leyes ilustradas llegan hasta los confines del Imperio y manifiestan la necesidad de instruir a la mujer.

Nos preguntamos: ¿Qué papel tuvo la mujer de la Colonia del Nuevo Santander en el proceso de pacificación del territorio? ¿Qué mujeres sobresalieron en aquel momento? ¿Qué actividad desempeñaron?

Buscamos documentación en archivos locales y nacionales, como el Archivo de Indias (en adelante AGI) y el Archivo General de la Nación de México (en adelante AGNM). Transcribimos, analizamos e interpretamos los documentos encontrados. Seleccionamos datos significativos relacionados con el quehacer de la mujer en aquel momento y lugar y reconstruimos una parte de la realidad histórica donde estaba la mujer, pero silenciada.

En los sucesivos apartados analizaremos la génesis de la Colonia, el asentamiento de la población y la búsqueda de la presencia de la mujer a través de la documentación existente que reflejase su actividad en la Colonia en los 20 primeros años desde su creación.

\section{Definitiva pacificación del Seno Mexicano}

La ocupación del Seno Mexicano se inició en I748 y dio origen a la Colonia del Nuevo Santander, último territorio del Virreinato de Nueva España en ser realmente colonizado. Con la ayuda del real gobierno y de un grupo de hombres

Lavrin, A.: Sexualidad y matrimonio en la América hispánica. Siglos XVI-XVIII, México, Grijalbo, I99I. 
INVISIBILIDAD DE LA MUJER MEXICANA EN LA DOCUMENTACIÓN DE MEDIADOS DEL SIGLO XVIII (COLONIA DEL NUEVO SANTANDER) HELENA VALES-VILLAMARÍN NAVARRO

acaudalados, el coronel José de Escandón y Helguera llevó a cabo el proyecto colonizador y organizó la estructura económica y social que caracterizaría la nueva provincia.

De acuerdo con el Gobierno central el coronel Escandón fundó 24 villas de españoles que consigue poblar con gran celeridad. El estrato social de los inmigrantes, excluidos el reducido número de hombres destacados por su posición social y económica, era muy bajo. La oferta de tierras y la ayuda de costa fueron decisivas para el efecto llamada de los futuros vecinos del Nuevo Santander.

Entre los documentos localizados y estudiados resulta fundamental para la comprensión de los procesos que dieron lugar al establecimiento del Nuevo Santander el Informe del Estado general de las fundaciones hechas por don José de Escandón en la Colonia del Nuevo Santander en I757 del Capitán Tienda de Cuervo, realizado tras la Visita a la que fue sometido el coronel don José de Escandón y Helguera. Este documento se utilizó como base para formular los cargos del juicio de residencia al que fue sometido el entonces gobernador y se convierte en un referente para estudiar la historia colonial gracias a la transcripción realizada por la doctora Patricia Osante y Carrera². A través de este extenso documento podemos apreciar los primeros trazos del perfil geográfico, de la demografía, del estado de las misiones y de las redes sociales y económicas de la Colonia y el estudio de la participación de las mujeres en los inicios de la vida del Nuevo Santander, principal objetivo de este artículo.

Como afirmaba Josefina Muriel3:

[...] se hace necesario seguir investigando, fomentar la obligación de conocer y divulgar esa parte de la cultura mexicana formada por las mujeres que participaron en la historia de manera silenciosa y silenciada, por la dificultad de acceder a los focos del saber $[\ldots]$.

\section{La mujer en los censos de población}

La vida de las mujeres de la Colonia del Nuevo Santander era similar a la de las mujeres del resto de las colonias, pero con circunstancias diferentes por la dureza del terreno, peligrosidad de los indios belicosos de alrededor y por ser años de asentamiento en los nuevos territorios en proceso de pacificación, donde tenían que combatir con el medio y con la amenaza india.

En el inicio de este proceso el número de hombres era sensiblemente superior al de mujeres. Transcurridas varias décadas, se modificó la proporción de hombres y mujeres, con un aumento considerable de la presencia femenina en las ciudades, equilibrada con el predominio masculino en zonas rurales y reales de

\footnotetext{
2 Osante y Carrera, P.: Poblar el Septentrión I y II. José Tienda de Cuervo, México, Instituto Tamaulipeco para la Cultura y las Artes y Universidad Nacional Autónoma de México, 2014.

Muriel, J.: Los recogimientos de mujeres. Respuestas a una problemática social novohispana, México, Instituto de Investigaciones Históricas, Universidad Autónoma de México, 1974.
} 
minas. Esta afirmación se demuestra con los datos aportados en estas gráficas que analizan la población masculina y femenina en la Colonia del Nuevo Santander a mediados del siglo xviII.

Cuadro i. Número de hombres y mujeres según datos extraídos del Estado General de las Fundaciones hechas por don José de Escandón en el Nuevo Santander4.

José Tienda de Cuervo. 1757

\begin{tabular}{|c|c|c|c|c|}
\hline & HOMBRES & MUJERES & NIÑOS & NIÑAS \\
\hline GÜEMES & 76 & 65 & 102 & 62 \\
\hline HOYOS & 72 & 60 & 95 & 67 \\
\hline AGUAYO & 6I & 59 & 80 & 67 \\
\hline LLERA & 72 & $7 \mathrm{I}$ & & \\
\hline ESCANDÓN & $7 \mathrm{I}$ & 70 & & \\
\hline HORCASITAS & 73 & 75 & & \\
\hline ALTAMIRA & 82 & 85 & & \\
\hline PADILLA & I09 & 75 & & \\
\hline SANTANDER & I4I & 100 & & \\
\hline SANTILLANA & 20 & I8 & & \\
\hline SOTO LA MARINA & 53 & 50 & & \\
\hline SAN FERNANDO & 78 & 79 & & \\
\hline REYNOSA & 60 & 58 & & \\
\hline CAMARGO & 9I & 93 & & \\
\hline MIER & $4 \mathrm{I}$ & 39 & & \\
\hline REVILLA & 59 & 59 & & \\
\hline DOLORES & 29 & 23 & & \\
\hline LAREDO & I5 & $\mathrm{I} 2$ & & \\
\hline BURGOS & 52 & 53 & & \\
\hline SANTA BÁRBARA & II4 & II7 & & \\
\hline PALMILLAS & 70 & 64 & & \\
\hline REAL DE LOS INFANTES & 43 & 42 & & \\
\hline & 1482 & 1367 & 277 & 196 \\
\hline
\end{tabular}

FuENTE: Elaboración propia.

Según el cuadro anterior, el total de población señalado es de 3.322 habitantes, de los cuales i.563 pertenecen al sexo femenino y r.759 al masculino.

Donde se da una mayor población masculina es en Santander, mientras que la población máxima femenina se encuentra en Santa Bárbara, con in mujeres frente a II4 varones. En Santillana y en Laredo hombres y mujeres apenas completan la centena. En cuanto a la población infantil la proporción de niños es bastante superior a la de niñas, aunque tradicionalmente el índice de supervivencia es mayor en las féminas que en los varones.

4 AGNM, Informe del Estado general de las fundaciones hechas por don José de Escandón en la Colonia del Nuevo Santander, México, I3 de octubre de 1757, Estado General de las Fundaciones. Provincias Internas, v. 172, expediente I6, hoja 285. 

HELENA VALES-VILLAMARÍN NAVARRO

En la gráfica se pueden comprobar los efectivos masculinos en los diferentes asentamientos recogidos por Tienda de Cuervo. Son mayoría las poblaciones que se encuentran en el tramo de 60 a 80 habitantes, mientras que en apenas 3 lugares la media varonil se sitúa por encima de la centena. Y en dos poblaciones llegan solo a 20 los efectivos masculinos.

Por lo que respecta a las mujeres, únicamente en Santa Bárbara la población femenina es superior a la centena, siendo mayoritaria la que se encuentra en los tramos entre 6o-8o, lo que nos confirma cierta proporción similar. Aunque el porcentaje de mujeres es de un $22 \%$ sobre el total de la población registrada en el año 1757 es bien significativo que su presencia en las fuentes escritas sea prácticamente nula.

GrÁficA I. Datos de población, hombres y mujeres, del Nuevo Santander. 1757

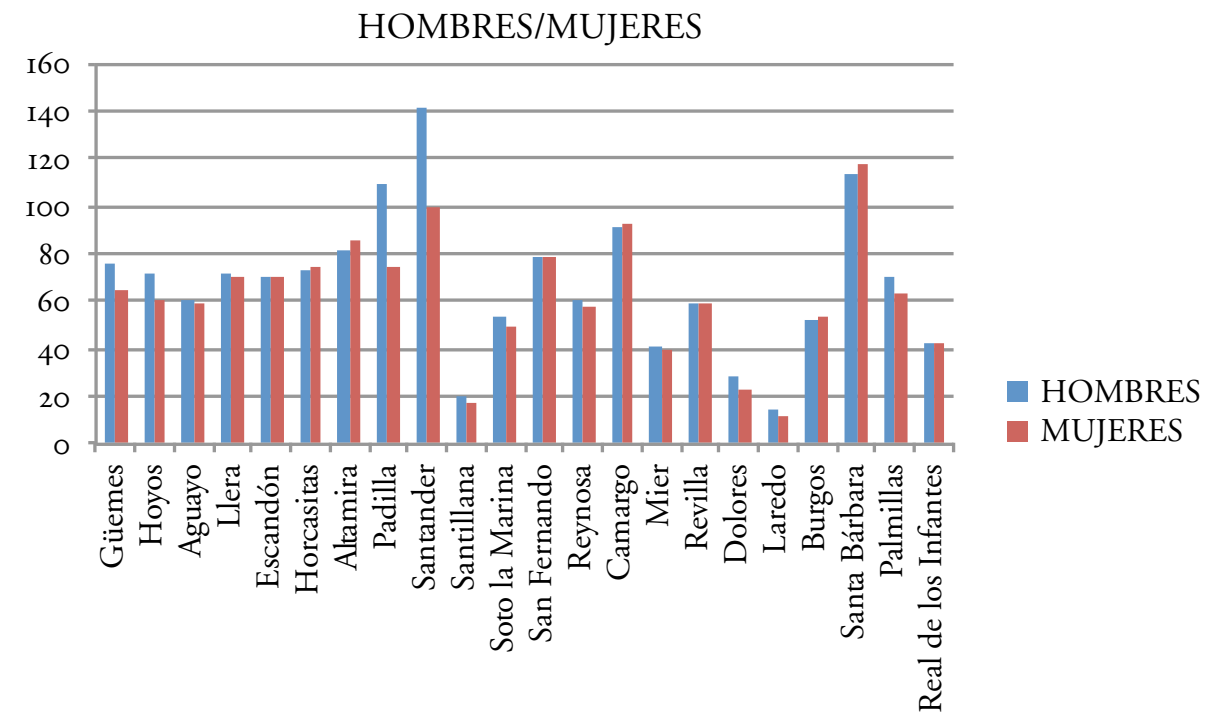

FueNTE: Elaboración propia.

\section{Oficios desempeñados por los habitantes de las Villas}

Queremos descubrir la presencia de las mujeres en los datos referidos a la actividad de la Colonia: qué oficios desempeñaban, qué actividad era la desarrollada por las viudas, si se dio la escolarización de las niñas... lo que significaría que era tenida en cuenta en los datos de población y en la vida del Nuevo Santander de manera intencionada o no.

En el estudio realizado por M. ángeles Durán 5 se nos muestran los datos sobre la estructura social en la España del siglo xvin y la situación de la mujer a

Durán, M. y CAPel, R.: Mujer y sociedad en España, I700-1975, España, Ministerio de Trabajo e Inmigración, Instituto de la Mujer, 1986. 
finales del Antiguo Régimen. En los datos referentes a la estructura productiva es patente la ausencia de la mujer en la Historia. El observador-administrador del siglo XVIII no mostraba ningún interés por saber si los agricultores, panaderos, bordadores o nobles eran hombres o mujeres y solo entre el estamento religioso aparecen claramente diferenciadas estas situaciones. La información que tenemos de los distintos censos realizados a partir de la segunda mitad del siglo XviII no nos ofrecen datos al respecto.

De la investigación llevada a cabo por Tienda de Cuervo en cada una de las Villas, hemos realizado un pormenorizado estudio de las profesiones de los hombres que se trasladan de otras tierras para asentarse en las Villas del Nuevo Santander.

Los datos globales permiten el conocimiento de la estructura laboral, económica y política, que sirvió de base para cimentar el desarrollo incipiente de dicha provincia. En este cuadro presentamos los datos de las profesiones de los habitantes de todas las Villas de la Colonia.

Cuadro iI. Profesiones registradas en cada Villa del Nuevo Santander. 1757

\begin{tabular}{|c|c|c|c|c|c|c|c|c|c|c|c|c|c|c|c|c|}
\hline & 胥 & 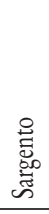 & $\frac{\frac{8}{0}}{\frac{\pi}{0}}$ & 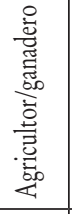 & $\begin{array}{l}\text { 号 } \\
\text { 莺 } \\
\text { 空 }\end{array}$ & 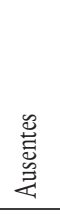 & 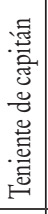 & 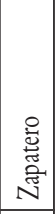 & 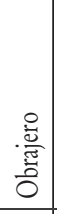 & 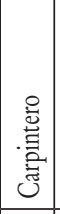 & 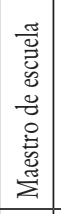 & 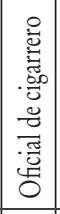 & 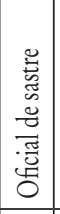 & 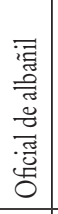 & 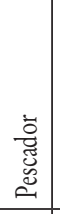 & 旁 \\
\hline Güemes & I & 2 & 2 & 53 & $\mathrm{I}$ & 17 & & & & & & & & & & \\
\hline Hoyos & I & & & 72 & 3 & 2 & $\mathrm{I}$ & 3 & $\mathrm{I}$ & $\mathrm{I}$ & $\mathrm{I}$ & $\mathrm{I}$ & $\mathrm{I}$ & $\mathrm{I}$ & & \\
\hline Aguayo & I & I & & 56 & & $\mathrm{I}$ & $\mathrm{I}$ & $\mathrm{I}$ & & & & & & & & \\
\hline Llera & I & I & $\mathrm{I}$ & 64 & $\mathrm{I}$ & 4 & & & & & & & & & & \\
\hline Escandón & I & I & & 54 & & 5 & & & & & & & & & & \\
\hline Horcasitas & 2 & I & & 62 & 4 & 4 & & & & & & & & & & \\
\hline Altamira & $\mathrm{I}$ & I & & 76 & 2 & $\mathrm{I}$ & & & & & & & & & I & \\
\hline Padilla & I & I & & 102 & $\mathrm{I}$ & 3 & $\mathrm{I}$ & & & & & & & & & \\
\hline Santander & I & & & $\mathrm{I} 33$ & 3 & 3 & & & & & & & & & & $\mathrm{I}$ \\
\hline Santillana & I & & & I9 & & & & & & & & & & & & \\
\hline Soto la Marina & I & I & 9 & 40 & & 2 & & & & & & & & & & \\
\hline San Fernando & I & I & & 69 & $\mathrm{I}$ & 5 & $\mathrm{I}$ & & & & & & & & & \\
\hline Reinosa & 2 & I & & $5 \mathrm{I}$ & 2 & 4 & & & & & & & & & & \\
\hline Camargo & I & I & IO & 67 & 6 & 4 & & & & & & & 2 & & & \\
\hline Mier & I & & & 36 & & 4 & & & & & & & & & & \\
\hline Revilla & I & & & 38 & & 19 & $\mathrm{I}$ & & & & & & & & & \\
\hline Dolores & I & & & 28 & & & & & & & & & & & & \\
\hline Laredo & I & & & $\mathrm{I3}$ & & I & & & & & & & & & & \\
\hline Burgos & I & I & 2 & 35 & $\mathrm{I}$ & 12 & & & & & & & & & & \\
\hline Santa Bárbara & & & & 80 & 6 & 26 & 2 & & & & & & & & & \\
\hline Palmillas & & I & & 55 & 4 & 9 & $\mathrm{I}$ & & & & & & & & & \\
\hline Real de los Infantes & I & & & 40 & & I & $\mathrm{I}$ & & & & & & & & & \\
\hline & 22 & 14 & 24 & $\mathrm{I} 243$ & 35 & $\mathrm{I} 27$ & 9 & 4 & $\mathrm{I}$ & $\mathrm{I}$ & $\mathrm{I}$ & $\mathrm{I}$ & 3 & $\mathrm{I}$ & I & I \\
\hline
\end{tabular}

Fuente: Elaboración propia. 

HELENA VALES-VILLAMARÍN NAVARRO

$\mathrm{El} 78 \%$ de la población se dedica a la ganadería y a la agricultura. La ganadería, desde la fundación de la provincia, es la principal fuente de ingresos garantizada que ofrecía a los inversionistas privados obtener jugosas ganancias, mediante importantes transacciones mercantiles que paulatinamente habían ido estableciendo con algunos comerciantes y hacendados independientes de las provincias del noreste y de otras más circunvecinas al territorio.

A pesar del alto porcentaje de varones dedicados a esta actividad agrícola-ganadera, la diversidad de oficios es patente (zapateros, obrajeros, carpinteros, cigarreros, maestros, sastres, albañiles, pescadores, etc.) aunque con porcentajes menores.

Un alto número de varones se dedicaban a labores militares. Dado que era una zona de frontera y por la belicosidad de los indios, se hacía necesario un cuerpo numeroso de protección de la población; además del capitán, sargento y soldados, toda la población de las Villas realizaba tareas defensivas en caso de necesidad en la misma milicia urbana.

El resto de profesiones eran las que desarrollaban en sus lugares de origen y también, posiblemente, en los nuevos asentamientos como complemento de su trabajo fundamental que serían las labores agrícolas o ganaderas.

Únicamente aparece un maestro en la Villa de Santo Domingo de Hoyos, profesión que desarrollaría en su escuela.

Es muy significativo que no aparezca mencionado en este Informe ningún oficio referente a la mujer. Es de suponer que esta omisión sea debido a que el autor sobrentiende que la mujer se dedicaba a «tareas mujeriles», es decir, labores domésticas y estas no son consideradas oficios ${ }^{6}$. Resulta extraño que no aparezcan trabajos que habitualmente desarrollaban las mujeres, como matronas o maestras de «Amigas». Estos eran trabajos habituales, básicos y necesarios desempeñados por la mujer en todo tiempo y lugar, especialmente con el porcentaje de población de mujeres y de población infantil por Villa. Muchas realizaban estas labores de una forma altruista, sin percibir un salario establecido, por lo que la retribución podría ser por trabajo realizado en el caso de las parteras.

Aunque la historia tradicional ha querido ver a las mujeres dentro de los muros de la casa, lo cierto es que han tenido una presencia activa fuera de ella. Siempre han existido espacios frecuentados por las mujeres que terminaron convirtiéndose en oficios propios de la sociabilidad femenina como acudir a la fuente o a los lavaderos para lavar ropa, hornos donde se cocía el pan, molinos para la molienda del grano, etc. La mujer estaba presente en el mundo del trabajo.

En el estudio de población y oficios de cada Villa, se señala con el término «ausente» aquellos casos en los que están la mujer y los hijos, si los hay, pero el varón está ausente. No se señala el motivo por el que el hombre no estaba, pero era la mujer la que sacaría adelante el núcleo familiar. Deberá desempeñar el trabajo y oficio necesario para poder mantener a la familia pero en ninguna Villa aparece reflejado el oficio o dedicación de la mujer cuando el marido está ausente.

6 Reder Gadow, M.: «Aproximación a una institución docente femenina: El Colegio de Huérfanas Nuestra Señora de la Concepción de María Santísima. Siglo xvinı», Baética, Facultad de Filosofía y Letras, Málaga, n. ${ }^{\circ} 7$ (1984). 
Gráfica II. Profesiones de los habitantes de las Villas de la Colonia del Nuevo Santander registradas por Tienda de Cuervo en 1757

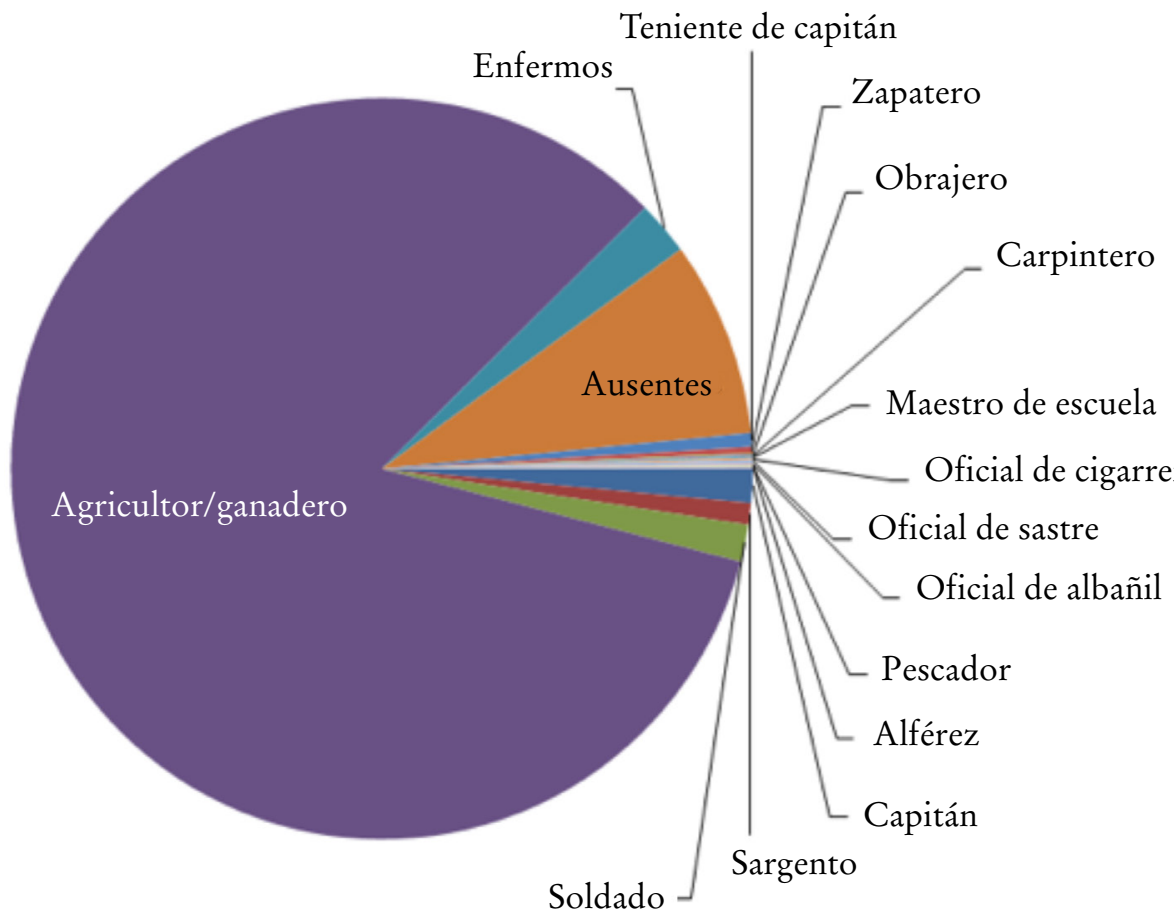

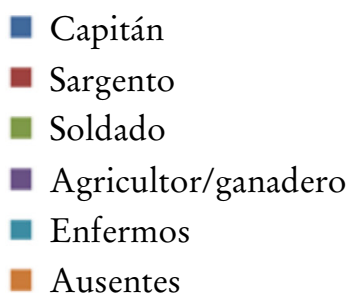

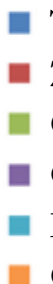

Teniente de capitán Zapatero

Obrajero

Carpintero Maestro de escuela

Oficial de cigarrero
Oficial de sastre

- Oficial de albañil

Pescador

Alférez

Fuente: Elaboración propia.

Lo mismo podemos decir de aquellos varones que aparecen en el Informe como «enfermos»; no se dice el motivo de la enfermedad y si pueden trabajar o no, pero podemos considerar que la mujer debería desarrollar el grueso del trabajo para sacar adelante la economía doméstica, sin embargo, tampoco en este caso se registra el oficio o trabajo de la mujer.

En el hogar, las mujeres trabajan al lado del marido y, en muchos casos, sus hijas contribuían a la subsistencia familiar, ya sea en trabajos familiares o extrafamiliares.

El trabajo en el campo era tarea de toda la familia, las duras condiciones de vida así lo exigían. La mujer será partícipe de tareas tales como pastoreo, vendimia 

HELENA VALES-VILLAMARÍN NAVARRO

o recogida del fruto de la cosecha. Pero no solo participaba en las labores agrarias en el seno de la familia, también eran asalariadas o incluso propietarias de tierras.

De forma mayoritaria, está relacionada con un trabajo exterior a su vivienda que supone, en la práctica, una prolongación del trabajo doméstico, pero que les permite el contacto con las demás mujeres del lugar, hablar y compartir las noticias.

Otro de los espacios públicos relacionados con el trabajo de las mujeres es el mercado, como vendedoras de los productos del campo que ellas mismas cultivan, cuidan y elaboran. Esta práctica es una constante que se ha mantenido desde la Antigüedad a lo largo de la historia. Los mercados, con mujeres vendedoras, compradoras, son un lugar de trabajo, pero también de encuentro e información de las mujeres ${ }^{7}$.

El sector que recoge más trabajo femenino es el textil, donde se incluye también la elaboración de vestidos, encajes y puntillas, actividad exclusivamente femenina o, simplemente, una actividad necesaria y básica para la vida ordinaria.

Las mujeres impulsan numerosas actividades. Algunos oficios fueron exclusivamente femeninos hasta los siglos XVII-XVIII como el de partera, comadrona o matrona. Tan vieja como la civilización es la historia de las matronas.

La opinión de Rodrigo de Castro, expresada en I594, perduró hasta el siglo XVIII: «Este arte no es apropiado para los hombres». Los médicos consideraron los cuidados del parto no dignos para su profesión, excepto en el caso de alumbramientos reales ${ }^{8}$.

Por lo anteriormente expuesto, podemos deducir que Tienda de Cuervo, en su profuso informe, no menciona los oficios de mujeres, y sí los de los hombres, por no considerarlos o por entender que los oficios femeninos son un complemento del trabajo importante del varón.

Entendemos que estos trabajos son básicos y fundamentales para el normal desarrollo de la vida social de cada una de las Villas, por lo que las mujeres desarrollarían estas tareas.

Existían de hecho estos oficios aunque no aparezcan en el Informe. Tienda de Cuervo no considera necesario reflejar los oficios femeninos siguiendo la consideración de la mujer en el siglo Xvin y la concepción masculina de la época. De nuevo debemos hacer historia leyendo en los «silencios» para descubrir la presencia real de la mujer.

\section{Los efectos igualitarios de las leyes ilustradas}

Las ideas ilustradas, divulgadas ampliamente durante la segunda mitad del siglo XVIII, consideraban a la educación como un factor de prosperidad nacional.

7 Martínez López, C.: «Oficios y saberes de mujeres», en Historia y sociedad, Granada, Universidad de Granada, 2002.

8 Reder Gadow, M.: «El trabajo de las mujeres, pasado y presente», en Actas del Congreso Internacional del Seminario de Estudios Interdisciplinarios de la Mujer, tomo III, Málaga, Diputación Provincial de Málaga, 1997. 
Sin embargo, la realidad era otra y los diputados americanos en las Cortes de Cádiz manifestaron sus opiniones en este sentido. El novohispano Ramos Arizpe, representante de la provincia de Coahuila, intervino en defensa de los intereses de las cuatro provincias de oriente 9 y se refirió a la lamentable situación en la que se encontraba la instrucción popular en aquellas tierras ${ }^{10}$.

La disminución de las luchas fronterizas con los indios del norte de México en el siglo xviıI permitió, como afirma José Ignacio Gallegos, un mayor desahogo de la vida de las Villas ${ }^{\text {II }}$. Pero la situación que comportaba la economía, fundamentalmente minera, y los presidios militares, con su población transitoria, dificultaron el desarrollo cultural de esta zona de frontera ${ }^{12}$.

Se han publicado numerosos estudios sobre las escuelas de primeras letras en la España del siglo XviII. Sin embargo, aun habiendo aportaciones relevantes ${ }^{13}$ no disponemos de un trabajo que tenga en cuenta las investigaciones más recientes. Es esa laguna la que pretendemos contribuir a llenar, aunque sea de forma parcial y puntual.

No parece muy aventurado afirmar que la escuela de primeras letras era una institución educativa que tenía una notable presencia en la sociedad española de finales del Antiguo Régimen. Ciertamente, bastantes pueblos no tenían maestro de niños, pero muchas localidades sí contaban con él. De hecho, existía una red de escuelas primarias relativamente amplia de iniciativa básicamente local.

En cambio, en el caso de la red de escuelas para niñas la situación era más precaria. En el Censo de Floridablanca la presencia de escuelas femeninas era

9 Además de Coahuila las otras tres provincias eran las limítrofes: Nuevo Reino de León, Nuevo Santander (hoy Tamaulipas) y Texas o Nuevas Filipinas.

1o Ramos Arizpe, M.: Memoria sobre el estado de las Provincias Internas de Oriente presentada a las Cortes de Cádiz, I8I2, México, Bibliófilos mexicanos, 1932.

" Gallegos, J.: Historia de la Iglesia en Durango, México, Editorial Jus, 1969.

${ }^{12}$ Luque Alcaide, E.: La educación en la Nueva España en el s. XVIII, México, Colegio de México, I970.

13 Saugnieux, J.: «Alphabétisation et enseignement élémentaire dans l'Espagne du XviIIE siècle», en Saugnieux, Jöel: Les mots et les livres. Études d'histoire culturelle, Lyon, Presses Universitaires de Lyon, 1986, pp. II3-I65 y I8I-218. VIÑAo FraGO, A.: «Alfabetización e Ilustración. Difusión y usos de la cultura escrita», Revista de Educación, número extraordinario: La educación en la Ilustración española, I988, pp. 275-302. Ruiz BERRIO, J.: «La educación del pueblo español en el proyecto de los ilustrados», Revista de Educación, número extraordinario: La educación en la Ilustración española, 1988, pp. i63-I9i. BARtolomé Martínez, B.: «Las escuelas de primeras letras», en Delgado CriaDO, Buenaventura (dir.): Historia de la educación en España y América, II: La educación en la España moderna (Siglos XVI-XVIII), Madrid, Fundación Santa María/Ediciones sM-Ediciones Morata, I993, pp. I75-I94 y 498-504. ViÑao Frago, A.: «Alfabetización y escolarización», en Delgado Criado, Buenaventura: Historia de la educación en España y América, II: La educación en la España moderna (Siglos XVI-XVIII), Madrid, Fundación Santa María, Ediciones SM-Ediciones Morata, 1993, pp. 159-I70, 483-490 y 777-786. Bartolomé Martínez, B.: «Las escuelas de primeras letras», en Bartolomé Martínez, Bernabé (dir.): Historia de la acción educadora de la Iglesia en España, I: Edades Antigua, Media y Moderna, Madrid, BAC, I995, pp. 6I2-620. Gimeno Blay, F. M.: «Aprender a escribir en el Antiguo Régimen», en Escolano Benito, Agustín (dir.): Historia ilustrada del libro escolar en España, I: Del Antiguo Régimen a la Segunda República, Madrid, Fundación Germán Sánchez Ruipérez, 1996, pp. 291-314. 

HELENA VALES-VILLAMARÍN NAVARRO

puramente testimonialit ${ }^{14}$ Sin embargo, según el Censo de Godoy, en un ı, $6 \%$ de los pueblos españoles había enseñanza para niñas y hay investigaciones que confirman la existencia de una débil red escolar destinada a mujeres a finales del siglo XVIII ${ }^{15}$.

En la Colonia del Nuevo Santander la educación femenina no pasó del nivel parroquial que se desarrolló en las zonas de misión. Durante esta centuria institucionalmente no hubo ninguna creación de colegios de mayor entidad que las pequeñas escuelas de alguna de las Villas ${ }^{16}$. En la relación dada por el obispo de la diócesis en 1765 , y que nos transmite el padre Cuevas ${ }^{17}$, constaba que no había ningún colegio femenino, ni convento alguno de monjas.

A pesar de las dificultades el proceso de escolarización había comenzado y la conciencia clara por parte de las autoridades locales de la importancia de alfabetizar y educar a la infancia llega hasta los confines de la Colonia ${ }^{18}$ :

El capitán don Miguel de Castañeda y Bergara, alcalde mayor por Su Majestad [...] bajo las superiores órdenes de nuestro soberano, cuiden, velen y celen el que en todos los poblados hallan escuelas públicas, para que el común, goza y tenga el beneficio de poner a sus hijos en donde aprendan los rudimentos cristianos de la ley de Dios, como a saber, leer y escribir para lo cual y con arreglo a el obedecimiento correspondiente $[\ldots]$ convoque y citen a el común de padres de familia para que con anuencia del párroco del lugar y mía, se les haga patente el cumplimiento de ambas majestades y se vea lo que cada uno ha de constituir para el pagamento del maestro que si hubiere de aunar, para que enseñe a los niños de este lugar, la doctrina cristiana $[\ldots]$.

En la Colonia del Nuevo Santander, lejos de la zona nuclear de Nueva España, en zona fronteriza y de creación tardía, con un estilo de vida pastoril y rural, sin instituciones educativas de entidad, también se dio la llegada de escribanos entre los colonos como Hermenegildo Sánchez García, autor de un manuscrito de crónicas de la Colonia, que refleja los comienzos de la educación en estos territorios recién pacificados y colonizados; así como algunos maestros, capitanes y tenientes quienes sirvieron de secretarios en los gobiernos escandonianos de las Villas ${ }^{19}$.

14 González Cruz, D.: Familia y educación en la Huelva del siglo XVIII, Huelva, Universidad de Huelva, 1996. Lorenzo Pinar, J.: La educación en Zamora y Toro durante la edad moderna: primeras letras y estudios de gramática, Zamora, Semuret, 1997.

is Laspalas, J.: «El ciclo escolar de la enseñanza elemental en Pamplona a principios del siglo XIX», Historia de la Educación: Revista Interuniversitaria, I2-I3 (1993), pp. 327-340.

${ }_{16}$ Vales-Villamarin Navarro, H.: Mujer y educación en el proceso colonizador del Nuevo Santander (Universidad de Málaga, tesis doctoral, documento no publicado), Málaga, 2014.

${ }_{17}$ Informe del visitador Gálvez al Rey Carlos III, transcrito por el padre Mariano Cuevas en su Historia de la Iglesia de México, El Paso, volumen I, México, 1928.

18 AGNM, Indiferente Virreinal, Caja 2827, expediente 23, 1789.

19 Agnm, Crónica del Nuevo Santander. José Hermenegildo Sánchez García. Profesor de primeras letras del Real de Borbón (Hoy Villagrán), expediente 55, I03 v. Fue formado por fray Juan José Rivera, maestro de escuela en el censo de los vecinos sin residencia, recién llegados a la Villa, levantado por el inspector Tienda del Cuervo en 1757. Aparece como maestro de escuela en el censo de Santo Domingo de Hoyos realizado tras la visita de Tienda de Cuervo. 
Tenemos noticias acerca de los primeros establecimientos de Primeras Letras y de algunos maestros que desarrollaron su tarea en estos últimos años del siglo XviII quienes debían atenerse a los requisitos recogidos en la Cédula Real de Carlos III del in de julio de I77I: «[...] buenas costumbres, limpieza de sangre y capacidad para la caligrafía y aritmética $»^{20}$.

Las ideas ilustradas consideraban a la educación como un factor de prosperidad nacional. Esta inquietud y deseo de los gobernantes llegó hasta la Colonia y, desde los primeros años de la fundación del Nuevo Santander, podemos ver la llegada de normativa que impulsaba la creación de escuelas para la instrucción de niños y niñas. Les movía la preocupación por la formación inicial, instrucción y capacitación adecuada de los maestros y la responsabilidad de los padres en la escolarización de sus hijos.

Son muchas las reales cédulas, decretos y bandos localizados que instaban a la escolarización de niños y niñas y que sustentan las afirmaciones de esta investigación. El interés de estos documentos, y de su ordenación, es destacable al tratarse de una fuente primaria y por recoger todos los legajos originales correspondientes a la fundación de escuelas en las Villas escandonianas existentes en el AGNM y en los archivos municipales del actual Estado de Tamaulipas.

En los bandos de la Villa de San Carlos piden la escolarización de los niños y se trataba de una escuela gratuita para todos: «... prohibiendo toda escuela particular a menos que sea la de niñas...». Casi todas las niñas recibían una educación rudimentaria en las escuelas llamadas de «Amigas»" de maestras particulares. Estas escuelas admitían muchachos pequeños y niñas hasta la edad de I2 años ${ }^{22}$.

Hemos localizado escritos que demuestran la existencia de escuelas y maestros, pero no existen noticias escritas de maestras que desempeñaran este oficio.

A finales del siglo Xvir las escuelas de niñas tenían una débil presencia en la sociedad. Una hipótesis verosímil, pero aún por verificar, sería que dichas instituciones acababan de nacer y fueron promovidas por las élites vinculadas a la Ilustración. En este sentido, sería muy diferente de la red de escuelas de niños que respondía a la demanda de instrucción de los padres y, al menos en algunas regiones, debía de contar desde antiguo con el apoyo de los municipios y las parroquias ${ }^{23}$.

20 Tanck de Estrada, D.: La Ilustración y la Educación en la Nueva España, México, El Colegio de México, 1985.

${ }_{21}$ Las Escuelas de Amigas constituían el primer nivel de enseñanza y equivalían a los actuales jardines de infancia o de educación preescolar. La formación que recibían era similar a la de sus propios hogares; jugando aprendían cuál sería su quehacer futuro. Al frente de estos parvularios se hallaban mujeres solteras o viudas que solicitaban permiso al Cabildo municipal para establecerse. Para muchas mujeres la asistencia continuada, durante dos o tres años, a estos parvularios, era su único contacto con la cultura.

22 Reder Gadow, M.: Morir en Málaga. Testamentos malagueños del siglo XVIII, Málaga, Universidad de Málaga-Diputación Provincial de Málaga, 1986.

${ }_{23}$ LASPAlas, J.: «La enseñanza de primeras letras en Navarra (1550-1650): balance provisional de una investigación en curso», en REDONDo, Agustín (dir.): La formation de l'enfant en Espagne aux XVI et XVII siècle, París, Publications de la Sorbonne Nouvelle, I996, pp. I47-I59. 


\section{Las viudas como cabeza de familia}

La viudez era un estado difícil para ambos sexos. El hombre se veía solo atendiendo las labores de la casa y cuidando y educando a los hijos. Pero especialmente resultaba difícil y duro para la mujer.

En los últimos años los historiadores de la familia se han ocupado con especial interés en la etapa de la viudedad como el momento en el que se muestra, de manera relevante, la postergación de la mujer, significando que tal estado no iba siempre asociado a edades avanzadas. Tras enviudar las mujeres, pocas trabajaban fuera del hogar salvo en la servidumbre, solo podían contar con los recursos económicos derivados de la mitad de los bienes gananciales del matrimonio y la devolución de la dote que en su día habían aportado al matrimonio.

Sin embargo, no todas las viudas quedaban en mala situación. Hay testadoras en este estado civil que contaban con un magnífico patrimonio económico. No hay que olvidar que la mujer casada jurídicamente estaba sujeta al marido, no pudiendo disponer libremente el destino de sus bienes. Las viudas, si no volvían a contraer matrimonio, asumían la condición de cabeza de familia y, por tanto, disponían de un caudal propio.

GRÁFICA III. Total de viudas y viudos sobre el global de la población de la Colonia del Nuevo Santander ${ }^{24}$

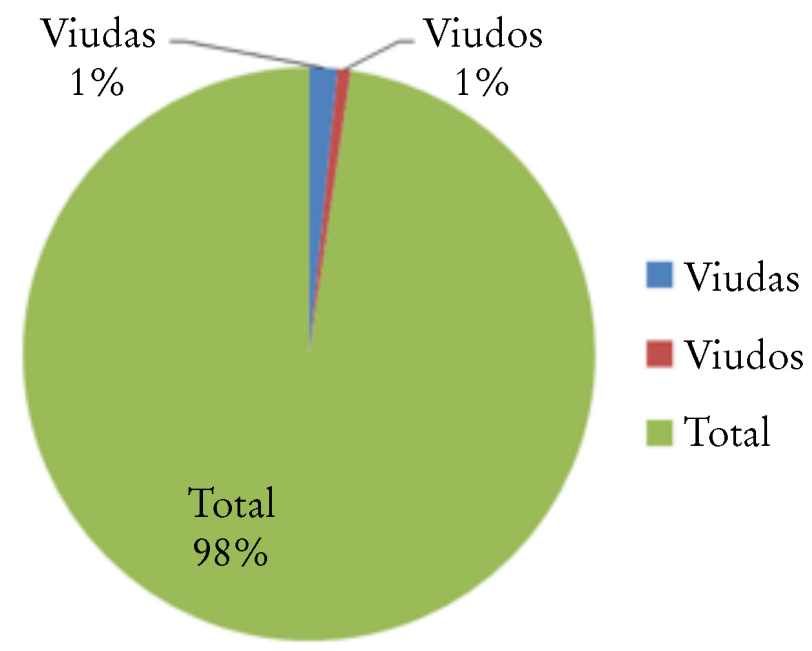

Fuente: Elaboración propia.

24 El estudio, expresado en gráficas, con el porcentaje de viudos y viudas de las 2I Villas a partir de los datos aportados en el Informe del Estado general de las fundaciones hechas por don José de Escandón en la Colonia del Nuevo Santander, puede verse en «Mujer y educación en el proceso colonizador del Nuevo Santander», versión electrónica de la tesis doctoral de M. ${ }^{a}$ Helena VALEsVillamarín Navarro. Universidad de Málaga. Repositorio Institucional de la UMa (RIUMA), 20I4, pp. 240-252. 
A partir del Estado general de las fundaciones hechas por don José de Escandón en la Colonia del Nuevo Santander, extraemos la información que nos ofrece sobre el número de viudas y viudos que hay en cada Villa de la Colonia. A través de gráficas observamos el porcentaje de viudas y viudos sobre la población total de cada Villa y el global de viudas y viudos en la provincia que, por lo general, no superan el $\mathrm{r} \%$.

En algunas Villas, como Escandón, no hay viudas ni viudos en el año en el que se realizó el censo, I757. Aquellas en las que se da un mayor porcentaje de viudas, con un $2 \%$, son Hoyos, Güemes, Aguayo, Santander, Soto la Marina, San Fernando, Dolores y Laredo.

Llama la atención el alto porcentaje de viudas de la Villa de Burgos con un $6 \%$ en relación al resto de Villas y con respecto a los viudos muestra un $\circ \%$. El porcentaje de viudos más alto, coincidiendo con el porcentaje de viudas, se da en la Villa de Real de los Infantes con un $2 \%$.

Las cifras son bastante oscilantes en las diferentes poblaciones salvo en la de Burgos en la que el número de viudas es muy superior al de las otras Villas y únicamente en la Villa de Escandón no se encuentran viudos ni viudas.

El estudio sobre las mujeres de la ciudad de México realizado por Arrom basándose en el Primer Censo de Población de la Nueva España de I79o, Censo de Revillagigedo, es uno de los más completos. Su investigación muestra el alto porcentaje de mujeres viudas. Aprovechando la rica información de padrones, testamentos y fuentes judiciales, establece las razones que motivaron este resultado: los factores de mortalidad, de nupcialidad y de emigración ${ }^{25}$.

En el Nuevo Santander, ateniéndonos a los datos proporcionados, el número de viudas es sensiblemente superior al de viudos, pero sería conveniente un estudio más profundo, analizando los parámetros demográficos por sexos-mortalidad, migración y ulteriores nupcias, aspectos que pueden abrir una nueva vía de investigación.

\section{La mujer neosantanderina}

Quizás quede cierto amargor cuando se acaba de leer esta investigación, sobre todo, si se lee desde la preocupación por la mujer y su incardinación en el mundo en igualdad de derechos con el hombre.

Es la constatación de una historia llena de dificultades para poner de relieve lo evidente. Pero hemos combatido ese sentimiento que acompaña a cualquier lectura que trate de la historia de las mujeres precisamente desde la dimensión liberadora de la historia que, mostrando la verdad, contribuye a que la verdad se cumpla. Lo aquí justificado es una aportación más en ese camino.

Esta investigación se asoma a la incipiente sociedad novohispana de la Colonia del Nuevo Santander, al interior de los hogares de las mujeres de las Villas, para descubrir sus motivaciones, su situación real.

${ }_{25}$ Arrom, S.: The Women of Mexico City, 1790-I857, Stanford, University Press, 1985. 

HELENA VALES-VILLAMARÍN NAVARRO

Podemos imaginar una mujer fuerte, que sustituye las ausencias o enfermedad del marido realizando labores agrícolas o ganaderas. Se hacía cargo del hogar y los hijos. Realizaba trabajos de partera o maestra, era tejedora y realizaba todas aquellas labores que, por exclusión, no aparecen registradas en el Informe de Tienda de Cuervo.

En su obra A room of one's own, Virginia Wolf realizó una denuncia, la ausencia de las mujeres en los libros de historia al uso y en las investigaciones que se habían realizado y se realizaban en aquel momento.

Aunque aparecían referencias a reinas, heroínas y santas, dichas referencias no hacían sino resaltar lo excepcional de una situación generalizada: el silencio en torno a la mujer y su mundo, o bien, solo constituían otras tantas formas de enfatizar las cualidades identificadas con lo femenino desde tiempo inmemorial.

Era necesario, como señaló Arlette Farge, «nombrar, identificar, medir la presencia de las mujeres en lugares, instancias y papeles que le son propios», y seguía diciendo «nos aparece como una etapa necesaria, un justo retornar de las cosas. Se ponen así al descubierto las categorías de lo masculino y lo femenino, hasta ahora sofocadas por un neutralismo sexual sólo provechoso para el mundo masculino» ${ }^{26}$.

La historia escrita no ha concedido a las mujeres de la Colonia el papel relevante que les correspondía y ha dejado sus actuaciones, siempre esforzadas, a la sombra de los logros cosechados por los hombres que las acompañaron en aquella aventura. De ahí que sea preciso llamar la atención sobre ese contingente femenino esencial en el nacimiento de la Colonia e interpretar los silencios en los escritos más que las alusiones que la historia nos aporta.

${ }^{26}$ Farge, A.: «La historia de las mujeres. Cultura y poder de las mujeres: ensayo de historiografía», Historia Social, n. ${ }^{\circ} 9$ (1991). 
